\title{
¿Territorios inteligentes, sostenibles e inclusivos? Enseñanzas de la experiencia española
}

\section{Joan Romero *}

\section{Resumen}

Se parte de la siguiente paradoja: nunca en la historia de España han existido mayor cantidad de leyes, normas y planes, lo que convierte en inexplicable el actual nivel de descoordinación y desgobierno territorial. Esta consideración inicial remite a otra de las cuestiones relevantes que preocupan al autor: en España buena parte de las competencias relacionadas con la ordenación del territorio corresponden a parlamentos y gobiernos autónomos, sin que esto signifque que los otros dos pilares del Estado carezcan de instrumentos y capacidades para desplegar políticas con gran impacto territorial. La notable complejidad que esto introduce, propia de todo Estado compuesto, requeriría dispositivos institucionales y una cultura política que favoreciesen la coordinación y la cooperación entre niveles y esferas de gobierno. La democracia, el buen gobierno y gobernanza territorial, la nueva cultura del territorio y del paisaje son condiciones para avanzar en la resolución de tales problemas complejos.

\section{Palabras clave}

Territorio inteligente; Política territorial; Gobernanza; España

\section{Abstract: Intelligent, sustainable and inclusive territories? Lessons from the Spanish experience}

This paper starts with the following paradox: in Spain, there are currently more laws, regulations and schemes than ever in history, which makes the current lack of territorial coordination and governance inexplicable. This initial consideration leads to another concerning issue for the author: in Spain, most powers pertaining to land planning are held by regional parliaments and governments; this does not mean, however, that the other two pillars of the State do not have instruments and powers to develop policies with a major impact on the territory. This leads to significant complexity, as happens in any composite State, and would require institutional mechanisms and a political culture promoting coordination and cooperation between various levels and spheres of government. Democracy, good territorial governance and a new culture of the territory and the landscape are essential to make progress towards solving issues of such complexity.

\section{Key words}

Intelligent territory; Territorial policy; Governance; Spain 


\section{Introducción}

Estamos inmersos en la crisis económica, social y política más devastadora que hemos conocido en décadas y los ciudadanos sufrimos con desconcierto, incertidumbre y temor sus consecuencias. Como algunos ya advertían en mitad del eufórico periodo 1997-2007, ahora se ha comprobado que no estábamos mejor que los demás, sino peor; que una parte muy importante del crecimiento económico de los años pasados tenía los días contados y descansaba sobre un modelo tan desequilibrado como insostenible (Romero, 2010; Pérez, 2011; Naredo; Montiel, 2011).

Además de los efectos de la crisis global España ha de afrontar ahora su específica situación. Con ello se cierra, de nuevo, un círculo de supuesto crecimiento virtuoso que además de enmascarar serios problemas estructurales, ha servido para poner a prueba muchos de nuestros mecanismos institucionales, la calidad de nuestra democracia, nuestra capacidad para desarrollar políticas públicas coherentes, nuestra cultura territorial y nuestra cultura política. Durante un prolongado e inusual período, al lado de algunos ejemplos de buenas prácticas y de buen gobierno del territorio, han predominado las sombras de la mala política, la desmesura, los excesos y la codicia. Pero, sobre todo, se ha evidenciado la enorme distancia existente entre el ámbito de la retórica y las políticas territoriales en muchos lugares concretos. Sin distinción de ideología, hemos incorporado toda la retórica referida a gobierno relacional, a gobernanza territorial, a desarrollo sostenible, a cohesión territorial, a planificación estratégica o a participación ciudadana. Sin embargo, la realidad indicaba otra cosa.

Durante década y media hemos ido dando contenido a una formidable paradoja: nunca en nuestra historia hemos tenido a nuestra disposición mayor cantidad de leyes, normas y planes. Hasta el punto de que resulta casi imposible poder hacer un seguimiento exhaustivo de todas las iniciativas legislativas e instrumentos de ordenación territorial. Y sin embargo, el nivel de descoordinación y desgobierno territorial tienen difícil explicación con estas normas. Algunos episodios incluso han superado con creces aquellas referencias tradicionales al desarrollismo de la década de los sesenta del siglo XX. Con la diferencia de que entonces no existían mecanismos democráticos y en esta etapa partimos de un marco democrático consolidado e integrado en una realidad geopolítica europea, de unas visiones culturales más elaboradas, de unas concepciones del territorio y el paisaje más cultas y de un grado superlativo de cobertura normativa.

Esta consideración inicial remite a otra de las cuestiones relevantes tratadas extensamente en otra parte (Romero, 2006; 2009): en España buena parte de las competencias relacionadas con la ordenación del territorio corresponden a parlamentos y gobiernos autónomos. Pero eso no significa que los otros dos pilares que son Estado, no dispongan de instrumentos y capacidades para desplegar políticas con gran impacto territorial. Esa notable complejidad, propia de todo Estado compuesto, requiere dispositivos institucionales y una cultura política que favorezca la coordinación y la cooperación entre niveles y esferas de gobierno. Lo cierto es que carecemos de mecanismos de coordinación y cooperación eficaces y que los que existen apenas son utilizados por los actores políticos concernidos. La estrategia política de la polarización ha prevalecido sobre la necesidad de construir algunos acuerdos políticos básicos que habrían favorecido la mejor gestión de la crisis y la propia reputación y solvencia de España.

No es seguro que vayamos a aprender de los errores del pasado. La historia reciente, y la menos reciente, indica que no hemos aprendido casi nada de episodios anteriores en los que ya conocimos estallidos de burbuja inmobiliaria; antes al 
contrario, en la última se ha superado con creces lo acontecido en el pasado. De nuevo, hemos seguido fielmente los pasos de aquella primera gran burbuja especulativa del bulbo del tulipán que atrapó a la sociedad holandesa del siglo XVII y que tan magistralmente describiera Charles MacKay (1852). Tampoco es seguro que la mayoría de la sociedad española y sus representantes políticos hayan tomado nota de que determinadas prácticas y políticas no debieran tener cabida nunca más. Sencillamente porque no son moralmente defendibles ni sostenibles.

Hace mucho tiempo que los pueblos más cultos de Europa han decidido transitar por los caminos de la buena política, de la cooperación institucional y de la nueva cultura del territorio. Ya disponemos de un muy buen catálogo de buenas prácticas a partir de enfoques renovados. El informe reciente de ESPON, buena muestra del estado del arte en esta materia, propone un título tan sugerente como alejado de la realidad española: territorios inteligentes, sostenibles e inclusivos (ESPON, 2010). Nuestra cultura política, nuestro escaso aprecio por los valores culturales asociados al territorio y al paisaje, nuestra querencia por el corto plazo y nuestra propia cultura social mayoritaria, han impedido hasta ahora la necesaria convergencia en la dirección apuntada en ese título y corroborada por el ya apreciable número de buenas prácticas en otros países de nuestro entorno.

En nuestro caso, el territorio, que ha sido el gran sacrificado en la larga etapa de crecimiento económico, no ha llegado a estar verdaderamente en la agenda política salvo en contadas ocasiones. Solamente ha sido considerado como un recurso y como un soporte físico para albergar actividades económicas. Sin distinción de adscripción política ni de esfera de gobierno, el urbanismo desbocado ha sido consentido, tolerado, amparado, legalizado y auspiciado, cuando no delibera- damente promocionado. Haya sido por indolencia política o por voluntad explícita, lo cierto es que en estos años de crecimiento sin desarrollo la política no ha hecho bien sus deberes. $Y$ con ella otros muchos actores y agentes y amplísimos sectores de la sociedad española que también han preferido sacar beneficio o mirar para otro lado aunque no ignorasen las consecuencias irreversibles de un proceso desenfrenado que ha asombrado al resto de países de Europa occidental.

No siempre se ha entendido que la defensa del interés general debe ser el núcleo central de las políticas públicas y la única hoja de ruta para cualquier responsable público. En estos años pasados el interés general no siempre ha sido el más general de los intereses en política territorial. Digo esto a propósito de las prácticas indeseables y de la destrucción irreversible de paisajes culturales en buena parte del territorio español durante década y media. $Y$ todo ello en medio de un espeso manto de difusa opacidad, de silencios y complicidades sociales cuyo resultado último es la inacción y la falta de controles rigurosos del Estado de derecho en defensa del territorio. La lógica del negocio a cualquier precio se ha antepuesto en numerosísimas ocasiones a la ética pública, a la defensa del interés general y al derecho a la gestión sostenible de recursos escasos y no renovables.

El riesgo que ahora existe es que en la actual etapa de recesión de nuevo el territorio sea el gran sacrificado. En la fase de expansión era para seguir creciendo a cualquier precio. Ahora, desde la esfera pública y desde la iniciativa privada, se reclama flexibilidad en la aplicación de normas e ignorancia de directrices con el pretexto de crear empleo en la fase recesiva. También existe el riesgo, cierto, de que muchos puedan pensar que se trata de un punto y seguido y que superado el mal momento, pasados unos años, podamos 
volver a las viejas prácticas a falta de un modelo productivo alternativo. Sin embargo, el actual momento debiera suponer un punto y aparte en la forma de entender la política, la democracia y el gobierno del territorio. Un final de etapa que en el futuro inmediato obligara igualmente a seguir hablando de construcción, pero en este caso de construcción de consensos básicos en torno a grandes cuestiones estratégicas y de construcción de mejores mecanismos de coordinación entre las diferentes partes que son Estado.

La política tiene mucho que decir en todo ello. La estrategia política de la polarización constituye hoy el principal obstáculo para que puedan prosperar algunos de esos consensos imprescindibles, junto a reformas inaplazables, y para favorecer una nueva generación de políticas públicas acordes con nuevos valores, una nueva cultura y nuevas formas e instrumentos para el buen gobierno del territorio. El abandono de una estrategia política de confrontación sistemática en la que se han instalado cómodamente los dos grandes partidos españoles desde hace años, debiera ser, a mi juicio, condición necesaria y previa para allanar un camino hoy prácticamente intransitable.

Nuestras mayores dificultades hace tiempo que habitan en el terreno de la política. Condiciona extraordinariamente el funcionamiento de un Estado compuesto, dificulta la transición hacia un nuevo modelo productivo asentado en nuevas prioridades y nuevos valores y es muy poco receptiva a incorporar nuevos enfoques inspirados en el buen gobierno y la gobernanza territorial democrática, hace tiempo asumidos y reclamados desde ámbitos académicos y profesionales (véase, por todos, Pascual y Godàs, 2010; Romero y Farinós, 2011). De ahí la insistencia en que los cambios han de operar en primer lugar en ese plano. Porque mientras esa incógnita no se despeje, no existirá la lealtad política e institucional imprescindible, los mecanismos institucionales de coordinación y cooperación no podrán demostrar toda su eficacia y los nuevos enfoques en favor del buen gobierno y la gobernanza no serán más que mera retórica. Será posible publicitar y anunciar proyectos y planes, pero no desarrollar una nueva generación de políticas públicas que hagan de la cohesión territorial el centro de atención preferente y sintonicen con lo mejor de las buenas prácticas ya ensayadas en otros países desarrollados.

\section{Democracia, buen gobierno y gobernanza territorial. De la teoría a los hechos}

En los países desarrollados, probablemente desde una óptica demasiado centrada en nosotros mismos, se ha hablado mucho de crisis durante las tres últimas décadas. Crisis y reestructuración del Estado-nación, crisis del Estado de Bienestar, crisis de la democracia, crisis de modelo de gobierno, crisis de modelo de crecimiento sin desarrollo... $Y$ sin ser plenamente conscientes de la gravedad de lo que acontecía a nuestro alrededor o en subcontinentes completos, sobre todo en nuestra Ribera Sur, lo cierto es que los debates sobre estas cuestiones han consumido, para bien, una gran cantidad de energías, en especial en el ámbito académico y político. Por esa razón, desde comienzos de la década de los ochenta del pasado siglo ha ido adquiriendo consistencia un nutrido grupo de debates, de alcance y recorrido desigual, pero de importancia, puesto que han acabado por impregnar muchas normas y políticas públicas.

Algunas tendencias de fondo, como la creciente sensibilidad por las cuestiones relacionadas con el medio ambiente y la gestión prudente de los recursos y el territorio, ya se iniciaron en la década de los sesenta del siglo XX en Estados Unidos. Más tarde tendría lugar el debate sobre los límites del crecimiento y la incorporación del desarrollo sostenible como objetivo. Mediada la década del los noventa se concretarían los prime- 
ros impulsos en la Unión Europea. Desde entonces, varios hitos significativos en el terreno cultural, simbólico y normativo han ido ganando terreno en todos los niveles de gobierno, y, aunque la eficacia en el ámbito de las políticas y los hechos hasta ahora haya sido discreta, nadie discute el liderazgo mundial ejercido desde Europa en este campo. Directivas, reglamentos, leyes, planes, estrategias, directrices, evaluaciones de impacto ambiental sectoriales y territoriales, evaluaciones ambientales estratégicas...Todas se han ido desarrollando de forma progresiva desde el ámbito comunitario a la escala local. Todas han ido incorporando valores y visiones que remiten a una nueva forma de gobernar, de relacionarse con el medio natural, de gestionar los recursos y de entender el desarrollo en los territorios. Todas indican progresos apreciables, cuando menos en el nivel formal.

Son muchas las cuestiones que se han abordado y que en ocasiones han tenido traducción en el ámbito de las estructuras de gobierno y de las políticas públicas relacionadas con el gobierno del territorio y el desarrollo sostenible. Los procesos de descentralización administrativa o de devolución de poder político a escalas subestatales han sido importantes en muchos países de la Unión Europea. El "retorno" de las ciudades y las regiones urbanas y metropolitanas como actores políticos indican la consolidación de un proceso de repolitización de la escala local y regional de gran trascendencia (Pike et al., 2011; Henderson, 2010). Puede hablarse de la emergencia de una nueva generación de políticas públicas en las que han ido ganando terreno nuevos enfoques y visiones mejor adaptadas a la nueva realidad geopolítica y a los cambios de nuestras sociedades. Por esa razón, desde hace más de una década se han ido abriendo camino nuevas estrategias de cooperación, vertical y horizontal, entre esferas de gobierno, nuevas iniciativas participadas por diversos actores para favorecer la promoción económica de territorios y nuevos enfoques estratégicos. La experiencia internacional en el desarrollo de pensamiento y acción estratégicos aplicados al desarrollo sostenible es amplia y ya podemos aprender de los fracasos y de los éxitos.

Pero también nuevas formas de entender y de ejercer el gobierno y de entender la democracia y la participación ciudadana. Durante estos años pasados, la "soberana capacidad" de los ciudadanos de ejercer todos los derechos reconocidos en cada Estado-nación se ha reducido o transformado, instalándose una percepción negativa entre la ciudadanía que bien podría quedar resumida como sigue: a) el Estado-nación tradicional ha perdido capacidad para garantizar derechos, seguridades y protección; b) en esa escala se ha debilitado la posibilidad de poder influir sobre decisiones colectivas; c) muchos piensan que la distribución igualitaria de poder político que el sistema democrático presupone ha evolucionado en dirección contraria a lo deseado y evidencia un creciente grado de concentración en manos de algunos actores y de determinados poderes que en ocasiones no responden ante ninguna instancia democrática; d) en el ámbito de la Unión Europea se ha extendido la percepción de que existe un notable déficit democrático.

En este nuevo contexto, donde global y local forman parte del mismo proceso, se ha acentuado el debate entre demos, demoi y comunidad política relevante. Debate que gana en intensidad en especial en aquellos Estados compuestos, como España, o de tipo federal, que tienen en la escala subestatal parlamentos con poderes legislativos. La globalización ha alterado la relación tradicional entre Estado, democracia y derechos de ciudadanía. Los Estados ven modificados sus perfiles tradicionales, pierden autonomía y ceden soberanía. Emergen nuevos actores políticos y nuevas fuentes de poder en sistemas cada vez más com- 
plejos, fragmentados y diversificados. Los ciudadanos reclaman más información $y$, en menor grado, más participación en los procesos de toma de decisiones. En especial, se reivindica la conveniencia de acercar la toma de decisiones lo más cerca posible de los ciudadanos, otorgando más protagonismo a nuevos ámbitos democráticos de decisión a escala local y regional. Proximidad y subsidiariedad serían los términos que mejor resumen estos procesos. Pero también será creciente la demanda de innovaciones democráticas, en especial en la escala local y metropolitana, capaces de superar las formas tradicionales de democracia representativa (Smith, 2009).

La traducción al ámbito de las políticas públicas ha abierto un amplio abanico de posibilidades y no menos encontrados debates que de forma resumida pueden concretarse en los siguientes: a) revisar el modelo de relaciones entre esferas de gobierno, el proceso de toma de decisiones y de construcción de consensos; b) crear espacios de negociación de conflictos; c) mejorar los mecanismos formales e informales de coordinación y cooperación, verticales y horizontales; c) facilitar la participación de actores privados en procesos de toma de decisión; d) crear nuevos espacios para la participación ciudadana. Pero, sobre todo, se ha sugerido la necesidad de revisar el papel del Estado y de entender el gobierno. Por eso algunos autores hablan de que en este proceso de democratización de los territorios es necesario repensar el papel de la esfera pública, repensar la democracia, revisar, democratizar y permeabilizar las políticas públicas y perseguir una mejor interacción entre esfera pública, esfera privada y sociedad civil. Dos procesos que han ido madurando y convergiendo en el tiempo lo sintetizan: de una parte el hilo conductor que enlaza buen gobierno, democracia y gobernanza, y de otra el relacionado con ordenación del territorio, gobierno del territorio, gobernanza territorial y cohesión territorial.

\section{Del gobierno jerárquico a la gobernanza}

Desde que el Banco Mundial lo pusiera en circulación, no puede decirse que el término gobernanza haya pasado desapercibido. $\mathrm{Y}$, aunque es cierto que sigue evidenciando un grado notable de ambigüedad, no lo es menos que su utilización ha ido adquiriendo densidad y relevancia en el campo de las ciencias sociales, en centros de pensamiento y en el seno de organismos públicos y privados. La propia Unión Europea lo hizo suyo a partir de que hiciera público el conocido Libro Blanco sobre la Gobernanza en 2001. Hoy, desde diferentes disciplinas, cuando se habla de gobernanza democrática, de gobernanza global, de gobernanza local, de gobernanza urbana o de gobernanza territorial, se remite inicialmente a un amplio y solvente cuerpo teórico, desarrollado a lo largo de la última década, que sugiere, en la escala respectiva, unas funciones diferentes para el Estado y una nueva forma de entender el papel del Estado, la acción de gobierno, la relación entre diferentes actores y la participación de los ciudadanos.

En la base, y con el trasfondo de una globalización creciente que todo lo altera, estaría la crisis del Estado burocrático y las limitaciones del Estado en el nuevo contexto, las crecientes dificultades presupuestarias y la "fatiga fiscal" en los países desarrollados, el "malestar", desconfianza y decepción ciudadanos, la insuficiencia de los mecanismos de representación democráticos y los profundos cambios de nuestras sociedades. La buena gobernanza democrática, en paralelo al cambio social, simbolizaría la transición desde estructuras verticales y jerárquicas a estructuras más horizontales, participadas, reticulares y porosas. No obstante, dado que gobernanza es un término que remite a proceso más que a modelo, sus dimensiones e indicadores varían en función de contextos específicos.

Más allá del interesante debate sobre sus diversas acepciones (hay muy distintas interpretacio- 
nes que hunden sus raíces en diversas tradiciones e ideologías), situados en la escala europea, los consensos sobre su significado son más amplios y todos remiten a los cinco principios orientadores recogidos en el Libro Blanco de la Gobernanza Europea que conviene recordar: apertura, participación, responsabilidad, eficacia y coherencia. La aplicación de estos cinco principios reforzaría los de proporcionalidad y subsidiariedad.

Leídos en clave europea, los principios reflejaban las propias carencias y limitaciones, más tarde acentuadas, del proceso de construcción de un proyecto político inacabado e inacabable. Sugerían un discreto código de mejor funcionamiento para un proyecto original que no podía ser federal pero que pretendía ser algo más que la mera suma de Estados. Se hacía de la necesidad virtud. Finalmente, enumeraban una serie de condiciones para el buen gobierno y la mejora de la coordinación entre actores políticos, todas de sentido común y que mantienen plena vigencia a cualquier escala, en los que algunos han querido ver mucho más de lo que allí se sugería. Dicho en otros términos, otras muchas visiones y propuestas de teóricos de la gobernanza sobre el papel y funciones de la esfera pública, la acción de gobierno o la implicación de actores privados en procesos de toma de decisiones, trascienden las sugerencias de aquel Libro Blanco que en su simplicidad contenía su mejor virtud. No podía ser de otra forma, dado que a la vista de distribución competencial y de fragmentación de estructuras de poder, tenían más posibilidades de prosperar formas de derecho blando e iniciativas flexibles y voluntarias de cooperación multinivel.

En el extenso trabajo académico en torno a qué se entiende por gobernanza democrática casi nadie desconoce las dificultades del proceso. Conviene recordar que en sus postulados muchos de sus defensores han advertido riesgos, nuevos problemas, zonas de sombra, contradicciones, y cuestiones relevantes no bien resueltas. Voces autorizadas como Renate Mayntz, Martin Shapiro, Jan Kooiman o Joan Prats, entre muchas aportaciones seminales recopiladas por A. Cerrillo (2005), han subrayado algunos relacionados con la necesidad de clarificar conceptos (buen gobierno, gobernación, gobernabilidad, gobernanza), con la dificultad para identificar los límites entre gubernamental y no gubernamental, para asignar responsabilidades y delimitar legitimidades, para superar posibles riegos de desafección o deslegitimación democráticas, para establecer mecanismos democráticos de rendición de cuentas o para garantizar una real participación de todos los actores políticos y sociales concernidos. En relación con el debate central sobre el significado de gobernanza democrática y sobre la relación Estado-ciudadano, ya analizado de forma extensa en otro lugar (Romero y Farinós, 2011), aquí se comparte el enfoque hace tiempo sugerido por Joan Prats:

"Contra la opinión, afirma Prats, que trata de diluir los gobiernos como un actor más en las estructuras de gobernanza, creemos que el principio democrático y de Estado de Derecho al que la gobernanza debe servir exige el reconocimiento de un rol, unas formas organizativas y de funcionamiento y una responsabilidad especial a las Administraciones Públicas. Éstas son actores en estructuras de interdependencia, pero no un actor más. No creemos en la gobernanza como sustituto del gobierno, sino en la gobernanza con gobierno, como modalidad de gobernación. La Gobernanza no puede diluir, sino fortalecer y legitimar la autoridad democrática" (Prats, 2005, p. 171).

A esta definición cabría añadir los factores avanzados por J.M. Pascual que, a su juicio, estructuran hoy la capacidad de organización y las metodologías e instrumentos para gestionarlos (Pascual, 2004): a) estrategia compartida entre los principales actores; b) modelo de interacción social; c) gestión en red de proyectos clave y com- 
plejos; d) existencia de unos objetivos comunes; e) asumir responsabilidades concretas; f) articular de manera efectiva las responsabilidades compartidas; y g) cultura de acción y compromiso cívico.

Sea cual sea el punto de vista, de este sugerente debate, que aún ha de tener amplio recorrido académico, pueden colegirse algunas conclusiones: a) la necesidad de reforzar los mecanismos de coordinación y cooperación, vertical y horizontal, especialmente entre actores políticos; b) la obligación de impulsar procesos de modernización del Estado, en la línea de los sugerido desde la propia OCDE; c) la exigencia de mejorar mecanismos de transparencia e información a los ciudadanos, y d) la conveniencia de impulsar mecanismos de participación ciudadana que superen vicios, sesgos o excesiva presencia de grupos de interés y sectores de la sociedad más organizados.

Podría decirse que el debate sobre la gobernanza territorial está ampliamente afianzado en el ámbito académico, pero encuentra resistencias para trasladarse al ámbito de las políticas. La notable distancia entre los contenidos de los textos de quienes abogan por nuevas formas de gobernanza y la realidad de los hechos en determinados contextos sociales e institucionales así lo demuestra al menos. Esta afirmación es particularmente apropiada en los países del Sur de Europa. Países de tradición democrática reciente donde la densidad institucional es baja, el tejido asociativo es escaso y el déficit en el ámbito de la cultura política del pacto y la cooperación es un gran condicionante.

\section{De la ordenación del territorio a la cohesión territorial}

El territorio, cuya atención se ha ido incorporando a la agenda política europea con enfoques renovados, empieza a ser percibido y gestionado de otra manera en muchos países de la Unión Euro- pea. Desde el propio método de asignación de Fondos Estructurales hasta el Libro Verde sobre la cohesión territorial, se aprecia este nuevo enfoque y este impulso. En el terreno normativo y en buena parte de las políticas con impacto territorial se constatan avances innegables: agua, desarrollo rural, protección del paisaje, espacios naturales, evaluación ambiental estratégica de planes y programas...la agenda territorial ha experimentado en Europa cambios apreciables y ha sido capaz de impregnar la mayor parte de políticas en las escalas estatal, regional y local. De nuevo, vuelve a existir distancia entre formal y real y se repiten diferencias entre Estados y entre regiones dependiendo de cada contexto cultural específico. Pero es difícil negar avances en la emergencia de una nueva cultura territorial hoy mayoritaria en algunos países.

En la Estrategia Territorial Europea se resumían e integraban buena parte de visiones y valores que reflejaban la complejidad de los nuevos procesos en curso y los efectos del cambio social y cultural; al tiempo que se sugería su traslación al ámbito de las políticas. La Estrategia de Lisboa (marzo de 2000) y la Estrategia Europea para un Desarrollo Sostenible (Gotemburgo, junio de 2001), marcaron la progresión de una interesante andadura que se ha concretado en la aprobación en Lepizig (mayo de 2007) de una Agenda Territorial de la Unión Europea que hace de la cohesión territorial el objetivo futuro. En esa misma reunión se aprobaba la Carta de Leipzig sobre Ciudades Europeas Sostenibles. El Cuarto Informe sobre la Cohesión Económica y Social (Comisión Europea, 2007) y el Libro Verde sobre la Cohesión Territorial (Comisión Europea, 2008) son las iniciativas más recientes que incluyen la cohesión territorial como pilar fundamental. Un sugerente hilo conductor que sigue apoyándose en las directrices básicas incorporadas en la Estrategia Territorial Europea de 1999 y que más de diez años después ha ganado respaldo social y 
académico y parece que va concitando mayor grado de apoyo político. Confiemos en que la recesión no diluya y posponga estos objetivos y enfoques que tanto esfuerzo han costado.

Así pues, buen gobierno, gobernanza, territorio, gestión prudente de los recursos, establecimiento de marcos coherentes para incorporar políticas sectoriales y diversidad territorial a escala regional son las ideas fuerza que han ido afianzándose en los marcos políticos que han de orientar estrategias y políticas de desarrollo en la Unión Europea. De este modo, mediante el original sistema de acuerdos y orientaciones estratégicas, los Estados miembros han querido evidenciar su voluntad política de avanzar y dar contenido a su forma de entender el desarrollo en los territorios. Pero la Unión Europea también ha querido mantener su posición de liderazgo mundial en el mantenimiento de un modelo social que ha hecho de la cohesión su elemento fundamental de referencia. Lo relevante es que se ha producido una convergencia gradual entre los grandes objetivos: mejorar las políticas de cohesión social, incorporar la dimensión territorial a las políticas públicas, dar importancia al principio de desarrollo sostenible en un contexto de cambio climático y prestar atención a las escalas regional y urbana como escalas relevantes para el impulso de políticas orientadas a la mejora de la competitividad.

Como explica Simin Davoudi, el concepto de cohesión territorial aporta una nueva dimensión al pretender aplicar los modelos sociales a lugares y territorios.

"[...] Sugiere que las oportunidades en la vida de un individuo están marcadas no sólo por las políticas sociales sino también por las políticas territoriales que afectan a la calidad de los lugares donde viven y trabajan las personas. Por lo tanto, los modelos sociales conceptualizan no sólo las formas en que las sociedades construyen la interdependencia social, sino también la manera en que éstas estructuran la interdependencia territorial.
[...] Al contrario que el término genérico de "modelo social", el de "cohesión territorial" transmite una clara dimensión normativa. Ésta exige: a) un modelo social específico que ponga énfasis en la reducción de las desigualdades e injusticias; objetivos que están supuestamente inmersos en el modelo de la sociedad europea; b) una extensión de principios individuales del modelo europeo a los lugares y a los territorios; y c) solidaridad no sólo entre los ciudadanos europeos, sino también entre los territorios europeos" (Davoudi, 2007).

Para abordar los retos colectivos de manera eficaz, el Libro Verde sobre la cohesión territorial sugiere adoptar enfoques integrados y apoyarse en tres principios inspiradores en la programación de las políticas comunitarias: compensar las ventajas de la concentración garantizando un desarrollo territorial equilibrado, mejorar la conectividad de los territorios, garantizar su acceso a bienes y servicios y mejorar la cooperación vertical y horizontal y entre políticas sectoriales y territoriales.

Las Directrices Estratégicas comunitarias en materia de cohesión para el periodo 2007-2013, más allá de su relevancia como marco orientativo para los Estados miembros y las regiones a la hora de preparar sus marcos estratégicos nacionales y sus programas operativos, sintetizaban gran parte de los progresos y visiones alcanzadas en Europa en relación con la cohesión y el desarrollo territorial sostenible. Hasta el punto de que, además de reforzar las directrices de crecimiento, competitividad, empleo, innovación, sociedad de la información y formación, incorporaba un importante capítulo a la dimensión territorial de la política de cohesión. Por primera vez se destaca en una decisión del Consejo que, en la política de cohesión, el aspecto geográfico reviste una especial importancia como elemento transversal y horizontal y que debe ser tenido en cuenta por los Estados y regiones cuando elaboren sus programas y concentren sus recursos en las prioridades. De hecho, indica una progresiva convergencia entre 
gobernanza y cohesión territorial. Y esta es, más allá de sus implicaciones presupuestarias, la principal aportación que puede hacer una Unión Europea que carece de competencias en materia de ordenación del territorio, pero que ha sido capaz de sugerir, innovar, promover y propiciar iniciativas, métodos de coordinación y marcos de actuación, integrando nuevos valores y nuevas prioridades que la sociedad europea ha ido haciendo suyos durante las últimas décadas.

Pero las pobres conclusiones y su improbable traslación al ámbito de las políticas en las escalas europea y estatal reflejan, aún mejor, las dificultades del proceso. El brusco cambio de expectativas de crecimiento de las economías europeas y las crecientes dificultades para sus ciudadanos a medida que la recesión económica se hace más profunda, alterará prioridades y directrices; aunque seguramente no hasta el punto de modificar visiones y culturas territoriales que ya parecen afianzadas en la percepción mayoritaria de los europeos. Y ello ya supone una contribución remarcable, pese a que el ritmo y la concreción de las políticas puedan experimentar dilaciones 0 modificaciones significativas.

\section{Territorio y paisaje: una nueva cultura}

En este contexto, nuestras sociedades experimentan una fase de retorno a los lugares, al territorio y al paisaje (Mateu y Nieto, 2008). Es una de las consecuencias más visibles de las dinámicas territoriales y de los procesos de cambio social y cultural en curso a los que antes se ha hecho referencia. Este retorno al territorio y al paisaje sería probablemente inexplicable sin hacer referencia a condicionantes y compromisos políticos de la propia Unión Europea y a la propia evolución de las nuevas funciones de los territorios rurales. Pero sería aún más inexplicable de no existir una larga tradición de diversas "miradas" y cultas tradiciones y escuelas que han dado continuidad y han proporcionado, en cada momento y con variaciones dependiendo de cada contexto cultural específico, distintos relatos sobre la relación del hombre con la naturaleza. También han contribuido al proceso la relación entre territorio, paisaje y (re)construcción identitaria.

Un dilatado proceso de construcción social en el que la cultura europea ha sido fundamental. Una rica tradición secular que en los últimos veinte años ha adquirido una recobrada intensidad y ahora, afortunadamente, nos desborda desde ámbitos académicos, cívicos, profesionales y culturales (Mata y Tarroja, 2006; Nogué, 2007). La diferencia con relación a momentos precedentes es que ahora estas miradas académicamente se han generalizado y socialmente se han democratizado. La sociedad y la academia lo ha hecho suyo y ya no se trata de proteger y conservar determinados hitos simbólicos, sino de entender el valor y las funciones del territorio y del paisaje de otra forma.

Tradiciones que se han visto enriquecidas con aportaciones que durante las pasadas décadas han ido construyendo un discurso alternativo, más culto, a procesos y dinámicas territoriales que ya no encajaban con los nuevos valores y visiones sobre el territorio. "El paisaje, más que imponerse, se elige" afirma Eduardo Martínez de Pisón. Y nuestras sociedades, con marcadas diferencias entre países, parece que habían elegido construir territorios banales, sin discurso, paisajes sin imaginario, no-lugares, ignorando la historia y cultura colectivas. $Y$ ante esa circunstancia, cada vez ha habido más ciudadanos que han pensado que las cosas se debían hacer de otra manera.

Este último retorno al paisaje se ha visto acelerado por dos hechos relevantes: las marcadas transformaciones que experimentan muchos territorios y paisajes y la extraordinaria velocidad con la que estos cambios se producen. En cuanto a la velocidad de los cambios, sin precedente en la historia de la humanidad, lo expresa muy bien Eugenio Turri: 
"[...] Las modificaciones del paisaje en el pasado solían ser lentas, pacientes, al ritmo de la intervención humana, prolongadas en el tiempo y fácilmente absorbibles por la naturaleza de los seres humanos: el elemento nuevo se insería gradualmente en el cuadro psicológico de la gente. Pero cuando esta inserción es rápida, como en los últimos años, la absorción se hace mucho más difícil" (Nogué, 2008).

Nada que añadir a esta contundente afirmación.

Es en este nuevo contexto en el que con lentitud, a veces exasperante, se va abriendo camino una nueva cultura del territorio y del paisaje. Lentamente, cultura, identidad, patrimonio colectivo y paisaje emergen y acaban impregnando directrices y normativas, desde la escala comunitaria a la local. Señal inequívoca de que los contextos sociales y culturales van madurando, única vía posible de que las políticas públicas sean finalmente eficaces. Antes se hablaba de rural como sinónimo de plural. En realidad, hoy rural es más bien la suma de plural, multifuncional y cultural. Muchos territorios europeos serán, básicamente, paisaje. Muchos espacios rurales son hoy en gran parte territorio de las clases medias urbanas. Como afirma John Berger, muchos territorios rurales ya no requieren necesariamente la presencia de agricultores (Berger, 2006, p. 250). A. Soja lo dice de forma aún más contundente cuando afirma que hasta lo rural es ya urbano (Soja, 2010). Y, sin embargo, los ciudadanos europeos, afortunadamente, prefieren mantener estos territorios vivos.

El Convenio Europeo del Paisaje, acordado en Florencia en el año 2000, simboliza y sintetiza muy bien esta comunión entre tradiciones, emergencia de nuevos valores y posibles enfoques alternativos para las políticas. Allí quedaban reflejadas nuevas aspiraciones para hacer frente a viejas frustraciones $\mathrm{y}$ a transformaciones no deseadas. Por eso se incorporaron referencias a la necesidad de desarrollar nuevos instrumentos de protección, gestión y ordenación de todos los paisajes. Pero, sobre todo, se ponía en relación naturaleza, cultura, patrimonio, identidad, al tiempo que se sugería la necesidad de establecer nuevas políticas y procedimientos para favorecer la participación activa de los actores políticos y sociales en su formulación y aplicación. Antes de esa fecha, algunos países ya habían demostrado una gran capacidad para relacionarse con sus paisajes de forma respetuosa. Otros muchos, en cambio, se han incorporado más lentamente. Sirva un dato para corroborarlo: el Reino de España ha ratificado el Convenio Europeo del Paisaje del año 2000 en marzo de 2008. Sea como fuere, desde la aprobación del Convenio, el desarrollo normativo sobre protección y nuevas formas de gestión del paisaje en Europa ha sido extraordinario.

Conocer bien tu país es condición necesaria para estimarlo. $Y$ estimarlo es condición necesaria, pero no suficiente, para garantizar que seremos capaces de apreciar el valor de paisajes culturales irrepetibles y de legar a la siguiente generación todo el extenso patrimonio paisajístico heredado, al menos en las mismas condiciones que lo recibimos de generaciones precedentes.

Muchos paisajes culturales de gran valor han sucumbido a las presiones incontenibles de la codicia. Los paisajes rurales devastados, abandonados o perdidos son ya irrecuperables. Pero otros muchos se mantienen vivos y en muchos casos son referente irrenunciable para una comunidad local, para una comarca o para una colectividad más amplia. Esos pueden preservarse. $Y$ de entre todos ellos aquí se proporciona una muestra excelente y variada para que cualquier persona con sensibilidad pueda apreciar la profunda relación existente entre historia, geografía, cultura e identidad. La relación existente entre pasado, presente y futuro.

En un bello libro, Eduardo Martínez de Pisón 
describe de forma magistral cómo entendemos hoy los paisajes rurales en Europa y por qué queremos preservarlos, mantenerlosy gestionarlos de otra manera. Al menos, qué significado otorgan hoy a sus paisajes los pueblos más cultos de Europa.

"El paisaje rural no es el territorio, afirma el autor. El territorio es el solar, el paisaje rural es el resultado de un proceso histórico. El paisaje rural es el legado de nuestro pasado colectivo. Legados, como lo son las artes, la arquitectura, el pensamiento o la literatura de un país. Los paisajes rurales poseen contenidos culturales propios que llegan a definir la personalidad de un municipio o de una región. Los paisajes rurales son testigos culturales de todo un pueblo. Como consecuencia de ese legado de conjunto, reflejan o contienen significativas señas de identidad de los pueblos que los habitan y por otros expresan el rostro y la cultura de la generación que tiene la responsabilidad de conservarlos y de entregarlos a la próxima generación.

El paisaje posee significados naturales e históricos. Pero también posee otros que remiten a referencias culturales y sociales, en sus identificaciones, en su personalidad, en sus valores. Es un espacio común de la vida colectiva de un pueblo. Vivido, pensado, habitado, cultivado, construido, cuidado, ¿destruido? [...]. Ignorar eso es mutilar el paisaje y la vivencia colectiva tan gravemente como pudiera serlo la tala de un bosque o el derribo de un pueblo \{...]. Los paisajes rurales son bienes culturales que sintetizan la experiencia vital de una colectividad. Pero son frágiles. Por eso precisan de mucha atención y protección. Atención y gestión culta e inteligente. Mantener vivos muchos territorios rurales precisa de políticas no solo territoriales sino culturales y de patrimonio. La política de protección del paisaje es también una política cultural..." (Martínez de Pisón, 2009).

Una mirada culta e inteligente significa tener capacidad de reconocer los valores visibles y ocultos, tangibles e intangibles, que tiene un paisaje aterrazado, unos márgenes de piedra seca, unos campos de cultivo mantenidos vivos aunque sus propietarios ya no vivan de ello, un regadío histórico con todo su rico patrimonio hidráulico que tantas generaciones anteriores han contribuido a construir y que hoy tienen valor patrimonial y cultural incalculable o un alcornocal milenario. Paisajes de piedra, paisajes de agua, paisajes arbolados, paisajes cultivados... paisajes con alma en definitiva.

Sabemos además que los paisajes culturales son incluso mucho más que el espejo del paso de culturas. Sabemos que el paisaje contribuye de manera determinante a la calidad de vida y el bienestar individual y colectivo de las sociedades; que paisaje y salud van unidos; como lo están también ciertas patologías y la pérdida traumática del sentido del lugar y la degradación del paisaje. Lo viene reiterando el autor de esta obra desde hace muchos años y lo han corroborado muchos expertos que se han ocupado de esta relevante cuestión desde diferentes visiones (Nogué, 2008). También sabemos que, cuando se habla de paisajes (de todos los paisajes y no solamente de los excepcionales) y de la necesidad de protegerlos y de gestionarlos de otra manera, han de tenerse muy en cuenta indicadores que nada tienen que ver con cuestiones que se pueden reducir a valores numéricos. Han de tenerse muy en cuenta otras consideraciones de tipo cualitativo relacionadas con el entorno vital de las personas, con valores afectivos, estéticos y simbólicos (Nogué, 2009). La tranquilidad es otro indicador fundamental cada vez más tenido en cuenta. Hasta el punto de que ya existen mapas de la tranquilidad en los que se subraya cómo el valor de la tranquilidad ayuda a la economía de un lugar, es bueno para la salud y reduce el estrés de las personas. El trabajo realizado por ejemplo en algunas áreas de Inglaterra, su envidiable esfuerzo por confeccionar sus Tranquility Maps y una extensa red de caminos tranquilos (Quiet Lanes) indica que algunas sociedades aprecian valores intangibles que son esenciales para garantizar su bienestar. 
Cualquier lector o lectora interesado puede acceder a las guías de caminos tranquilos o a la relación de condados más apreciados de Inglaterra precisamente porque cuentan con niveles de tranquilidad muy altos (Campaign to Protect Rural England, 2006).

\section{¿España es diferente?}

Llegados a este punto, parece pertinente hacerse dos preguntas: ¿Hasta qué punto se participa en España de estas corrientes culturales de fondo? ¿Cómo se han acompasado estos cambios a nuestra realidad política, social y cultural? Por diversas razones, el ejemplo español no forma parte del grupo de países que pueda ofrecer todavía una aceptable relación de buenas prácticas de buen gobierno y gobernanza territorial. Las dinámicas territoriales de los últimos años han evidenciado los grandes retos aún pendientes: hacer de la coordinación y la cooperación entre esferas de gobierno una costumbre, superar la cultura territorial aun mayoritariamente "desarrollista" y reducir la excesiva distancia entre los textos legales, los contextos sociales específicos y las prácticas territoriales.

Paradójicamente, como antes se indicaba, nunca han existido tantas directivas, leyes, reglamentos e instrumentos relacionados con la ordenación del territorio, la protección del paisaje, la evaluación de impacto ambiental o la evaluación ambiental estratégica. $\mathrm{Y}$, sin embargo, nunca se ha hablado tanto como ahora de falta de coordinación, de desgobierno territorial, de malas prácticas e incluso de corrupción asociada al urbanismo. También se habla de "captura" de la política y de oclocracia, al estilo de las otras situaciones homólogas en países de América Latina. Se ha llegado a hablar incluso de crisis de modelo de gobierno del territorio. En la práctica, España se ha alejado de las directrices que desde hace tiempo se sugieren en Consejos Europeos y en otras instancias comunitarias, estatales, regionales y locales en ma- teria de gobernanza territorial democrática. En otros casos se demora o ignora la aplicación de normas. Un rasgo cultural muy significativo que obliga a pensar sobre las causas últimas y a no asumir de forma acrítica paradigmas o modas que poco tienen que ver con nuestra realidad política, social y cultural.

España se incorpora muy lenta y tardíamente al grupo de países que han decidido hacer suya una nueva cultura del agua, del territorio y el paisaje. Se inician tímidamente las primeras señales en las que emergen otras visiones que reclaman otras prácticas, otras formas de entender la política y una gestión más prudente del territorio y el paisaje. El propio cambio social, la renovada importancia de la escala local y de los lugares y los procesos de recomposición social en muchos territorios han contribuido a que pueda hablarse de inicio de una nueva etapa. Los territorios son cada vez más plurales. En cada lugar hay cada vez más actores diferentes, con distintos valores y prioridades asociados al paisaje y a los territorios rurales. Algunos de ellos han hecho suyas muchas de las corrientes de fondo antes destacadas. Eso explica la coexistencia de miradas y culturas territoriales diferentes en un mismo lugar, la aparición de centenares de movimientos sociales que reclaman otras formas de gobierno del territorio, la emergencia de una nueva geografía de los conflictos por actuaciones sobre el territorio $y$, en menor grado, una nueva generación de políticas más acordes con el buen gobierno del territorio.

Pero sigue habiendo una distancia sideral entre las visiones teóricas y nuestra realidad política. Entre el plano virtual y el real. Una realidad que dificulta el progreso de buenas prácticas de gobierno del territorio. Además de enfrentarse con nuestros fundamentos culturales e históricos, o debido a ellos, las propuestas de buena gobernanza territorial o de buen gobierno chocan con el 
muro muchas veces infranqueable de las estrategias de polarización de los partidos políticos. Esta circunstancia reduce dramáticamente los espacios de cooperación y limitan y dificultan las posibilidades de construcción de consensos básicos. De otra parte, esas propuestas, elaboradas con solvencia desde los ámbitos académico y profesional, no encuentran el impulso imprescindible en la política para su puesta en práctica.

Un somero análisis de muchos discursos, actitudes e iniciativas políticas revela que algunos actores políticos relevantes hacen de la estrategia de la confrontación con otras esferas de gobierno su mejor recurso político. A veces la apelación a las distintas instancias judiciales es el complemento indispensable. Sin valorar las consecuencias irreversibles sobre el territorio, sin reparar en los efectos sobre la calidad y densidad de la democracia y sin evaluar adecuadamente el daño causado a los mecanismos institucionales de coordinación y cooperación, esenciales por otra parte en un Estado compuesto, se utiliza como herramienta política el urbanismo, el agua, la gestión del litoral, la dotación de infraestructuras, la gestión de espacios naturales, el gobierno de las áreas metropolitanas, la financiación o la puesta en marcha de planes de ordenación del territorio en la escala supramunicipal. Y quienes así conciben la política debieran saber que la gestión de recursos hídricos o la política territorial en un Estado compuesto no pueden desarrollarse a golpe de recurso contencioso o de recurso al Tribunal Constitucional. Tampoco a golpe de decreto y de decisiones unilaterales. También debieran ser conscientes de que los consensos y la lealtad institucional no se aprueban por una ley o un decreto, sino que se construyen, casi siempre con dificultad, si se es capaz de situar a los ciudadanos y al interés general en el centro de las decisiones políticas de amplio alcance.

\section{¿Hay que abandonar toda esperanza?}

El proceso de construcción de un Estado compuesto en el que la coordinación y la cooperación entre distintas esferas de gobierno sea una costumbre aún requiere tiempo, voluntad política e interés por recuperar la cultura del acuerdo. Hemos despilfarrado territorio y hemos devastado paisajes culturales contando con amplio apoyo social e incluso en ocasiones legitimando en las urnas actuaciones y culturas completamente inapropiadas. Hemos alterado protocolos esenciales del Estado de derecho y hemos puesto a prueba la calidad de nuestra democracia. Y, aunque predominan las sombras sobre las luces, no por ello hay que abandonar toda esperanza, como reza en la inscripción de la puerta del infierno de Dante.

De forma reiterada se muestra cierta predilección por achacar el actual estado de cosas y la previsible evolución a actuaciones de diferentes gobiernos, preferentemente conservadores, en la escala regional y local. Pero esta argumentación no sirve para entender otras claves fundamentales de dinámicas y procesos con fuerte impacto territorial ocurridos en España. Más que en la orientación ideológica, la explicación hay que buscarla, en primer lugar, en la ausencia de mecanismos eficaces de control democrático, de rendición de cuentas y de transparencia de las administraciones públicas. En segundo lugar, en la existencia de una cultura democrática de baja densidad, tolerante con prácticas y episodios de mala política cuando no de corrupción. En tercer lugar, en la existencia de una cultura territorial mayoritariamente productivista. Los procesos desmesurados de urbanización insostenible que han tenido lugar en España en los años pasados han tenido lugar en contextos específicos en los que dichas propuestas estaban socialmente legitimadas por la mayoría y gozaron de un amplio consenso social. 
Salvo excepciones honrosas y casi siempre desde posiciones política y socialmente minoritarias en cada lugar, nadie se ocupó con la atención debida de la devastación de paisajes culturales, del despilfarro de suelo, de los problemas de abastecimiento o escasez de recursos (en especial agua y energía), de las dificultades para afrontar la recogida de residuos, de la provisión de servicios públicos, de los problemas de seguridad asociados al modelo de urbanización dispersa, de las dificultades presupuestarias a medio plazo para hacer frente al incremento de gastos cuando ya no hay territorio por vender o está colmatado. Prevaleció el corto plazo, la falsa idea de progreso y el ciclo político.

Pero, aunque no sería del todo cierto atribuir, en exclusiva, la responsabilidad a los titulares de los diversos gobiernos y parlamentos, eso no significa que no quepa atribuirles una responsabilidad política ineludible. Naturalmente, los gobiernos regionales han sido en gran medida políticamente responsables de lo acontecido en España. En primer lugar, por acción u omisión de iniciativas legislativas y reglamentarias en la escala adecuada. Sobre todo, cuando de forma intencionada han renunciado a sus propias competencias para establecer marcos de ordenación vinculantes a escala supramunicipal. En segundo lugar, de haber creado el clima propicio -no exento de opacidad- para que los intereses del sector inmobiliario hayan encontrado todo tipo de facilidades. Algunos grupos de interés, instalados en los márgenes del poder político, han generado un nivel remarcable de connivencia, de colusión de intereses y de confusión preocupante de papeles. Este clima es el que ha propiciado la aparición en España de episodios bien conocidos de "captura" de políticas (Matsuda, 2007). En tercer lugar, de aceptar, aprobar y tramitar propuestas de urbanización que en muchos casos no eran procedentes.
En este contexto institucional, en ausencia de marcos de ordenación supramunicipales, los gobiernos locales impulsaron y propusieron miles de iniciativas, muchas de ellas tan incoherentes como insostenibles, muchas de las cuales fueron finalmente aprobadas por la autoridad regional competente en la materia. Los representantes del "bloque inmobiliario" supieron aprovechar muy bien la favorable coyuntura económica y el contexto social e institucional para consolidar un modelo territorial que nos ha situado al borde del abismo. Los propietarios y el conjunto del "bloque inmobiliario" no fueron cuestionados, y tampoco sus prácticas, por la mayoría. Incluso voces autorizadas de la profesión y sus representantes defendieron las posiciones urbanizadoras tradicionales, apoyadas en un discurso técnico en el que los impactos ambientales quedaron reducidos a mero trámite administrativo.

Tal vez pueda hablarse del inicio de una nueva etapa en España. La coincidencia en el tiempo de un conjunto de grandes tendencias de fondo, propias de las sociedades desarrolladas, unido al debate social sobre las negativas consecuencias, económicas, sociales, culturales y políticas del desgobierno territorial, contribuyen al proceso de maduración de contextos culturales, condición necesaria para que las normas demuestren toda su eficacia y coherencia. La emergencia de nuevos actores políticos en la escala regional y local, la demanda creciente de más democracia y mayor participación ciudadana en los procesos de toma de decisiones, la emergencia de nuevos valores ambientales y el "retorno" al paisaje y a los territorios rurales, van creando condiciones más propicias para evitar actuaciones insostenibles y para que directivas, recomendaciones europeas y legislación y normativa españolas se vayan afianzando.

¿Cuáles son los elementos que permiten afirmar aquí que nos encontramos al inicio de un nuevo y 
prometedor periodo en el que emergen actitudes y propuestas que reclaman otra forma de gobierno del territorio y una nueva cultura del territorio y de protección del paisaje? En primer lugar, la posición más activa demostrada por amplios sectores de la comunidad académica y profesional. Durante estos años, la producción científica y el esfuerzo de divulgación desplegados han sido impresionantes. En este contexto social mayoritario los discursos que desde el ámbito académico y profesional proponen una nueva cultura del territorio fueron inicialmente muy minoritarios, pero una década después incluso han desbordado el propio ámbito académico para situarse claramente, y cada vez de forma más consistente, en un ámbito más próximo al terreno de las propuestas y del compromiso cívico. El Manifiesto por una nueva cultura del territorio, impulsado en 2006 por un grupo de profesores y profesionales, no es más que una muestra de una corriente pluridisciplinar mucho más amplia que además entiende que todas las miradas académicas y todo compromiso son imprescindibles. El Manifiesto fundacional por una nueva cultura del agua o los manifiestos y declaraciones en favor de una mejor protección del territorio o el paisaje, son otras muestras de esta actitud proteccionista y propositiva.

En segundo lugar, la extraordinaria atención prestada por los medios de comunicación a todas las cuestiones relacionadas con especulación urbanística, con prácticas insostenibles en materia de urbanismo y ordenación del territorio y con casos de corrupción urbanística. En menos de un lustro, se ha producido un cambio que ha sido determinante dado el papel fundamental de los medios de comunicación en la formación de percepciones sociales. Así como hace años los medios apenas prestaban atención a determinadas cuestiones que tenían lugar en territorios rurales pero no asociadas al urbanismo (trazado de infraestructuras o ubicación en zonas rurales de activi- dades con fuerte rechazo social como centros penitenciarios, plantas de residuos o trazado de líneas de alta tensión), desde hace años su atención se ha orientado de forma preferente a informar sobre procesos que implican transformaciones intensas relacionadas con el urbanismo desbocado y que se entienden indeseables.

En tercer lugar, el impresionante movimiento ciudadano que ha ido adquiriendo relevancia en toda España durante los últimos años. Desde cada lugar, muchos actores sociales expresan también sus reivindicaciones a favor de otra forma de entender y gestionar el territorio. La experiencia de los "salvemos" y la proliferación de plataformas, asociaciones, movimientos e incluso de Fundaciones culturales "en defensa" o de "custodia" del territorio y de los recursos naturales, son expresión de la creciente recomposición social y cultural y de un amplio proceso de empoderamiento cultural en muchos lugares. También de una nueva geografía de los conflictos, expresión de este inicio prometedor de un proceso de maduración de contextos culturales. Como en otros países europeos, como por ejemplo en Francia, donde se ha producido un intenso movimiento de protesta y reivindicación desde los territorios (Subra, 2007), también en España se está produciendo una clara transición de movimientos sociales del tipo "aquí no" (Nel.lo, 2003) hacia aquellos que ya reivindican "así no", y el balance provisional de los últimos años es más que significativo en su dimensión sustantiva, relacional, simbólica y política (Alfama, Casademunt et al., 2007; Cruz i Gallach, 2010).

En cuarto lugar, los poderes públicos también han iniciado una nueva etapa que probablemente también es de no retorno. Gobiernos y parlamentos impulsando una nueva generación de iniciativas legislativas que antes o después acabarán por demostrar eficacia. Desde la modificación de la legislación básica en materia de suelo hasta la nueva generación de planes urbanísticos munici- 
pales, pasando por la profusa producción legislativa y normativa en la escala regional, en un contexto cultural menos permisivo tendrán mayor repercusión. Por otra parte, el poder judicial también ha reforzado su capacidad al tiempo que se va incorporado a esta forma de entender la relación existente entre cultura, territorio y actividad productiva. La simple lectura de las memorias correspondientes a 2006 y 2007 , en especial la última, elaboradas por la Fiscalía Coordinadora de Medio Ambiente y Urbanismo (Fiscalía General del Estado, 2007), así como las cada vez más numerosas sentencias de distintos Tribunales Superiores de Justicia y algunas muy significativas del Tribunal Supremo, son una demostración esperanzadora de que también algo está empezando a cambiar en el poder judicial en relación con estos temas.

\section{Conclusiones. Territorios con cultura, territorios con discurso, territorios con futuro}

Durante los últimos años muchos países de la Unión Europea han demostrado una clara intención de incorporar nuevas formas de gobierno del territorio y de gestión del paisaje. El balance de la última década y media demuestra que en España todavía estamos muy al inicio de un largo camino, que no suele ofrecer atajos, que siente las bases de unos mecanismos eficaces de coordinación y cooperación entre las partes que son Estado y de hacer madurar contextos específicos a favor de una gestión prudente del territorio y de los recursos para dejar atrás una cultura territorial, hoy mayoritariamente "desarrollista", que permita reducir la distancia existente entre los textos legales, los contextos culturales y las prácticas territoriales.

España debe incorporarse al grupo de países que han decidido hacer suya una nueva cultura del territorio. Aunque casi todo el camino está por recorrer, parece que el contexto cultural empieza a emitir las primeras señales en las que emergen otras visiones que reclaman otras prácticas y una gestión más prudente del territorio. El propio cambio social, la renovada importancia de la escala local y de los lugares y los procesos de recomposición social en muchos territorios han contribuido a que pueda hablarse de inicio de una nueva etapa. Los territorios son cada vez más plurales. En cada lugar hay cada vez más actores diferentes, con distintos valores y prioridades asociados al paisaje y a los territorios rurales. Eso explica la coexistencia de miradas y culturas territoriales diferentes en un mismo lugar, la emergencia de una nueva geografía de los conflictos por actuaciones sobre el territorio y una nueva generación de políticas más acordes con el buen gobierno del territorio. Pasado un tiempo, la sociedad española percibirá con mayor claridad las consecuencias presentes y futuras de una década y media de desmesura, de excesos y desgobierno territorial. Consecuencias a varios niveles, desde las relacionadas con la excesiva dependencia de la actividad económica y el empleo respecto al sector de la construcción residencial, ahora evidentes, hasta la desaparición irreversible de referentes de nuestra historia y cultura colectivas.

Pero algo está empezando a cambiar en el imaginario colectivo de la sociedad española. Incluso antes de que el ciclo económico anunciara una paralización de la construcción residencial, ya existían voces que expresaban su desconcierto y su descontento con las formas y con el fondo de un proceso desbocado que no anunciaba un buen final. De otra parte, iniciativas recientes adoptadas por distintos poderes del Estado y por parlamentos y gobiernos regionales y locales en materia de urbanización, de ordenación del litoral, de protección del paisaje y otros anuncios de planificación territorial supramunicipal, son también buena muestra. Indica que las cosas se pueden hacer de otra manera sin comprometer por ello la 
actividad económica o el empleo. Sólo se requiere voluntad política para promover un desarrollo territorial más coherente y sostenible.

Será a partir de estas expresiones desde donde podrán construirse discursos consistentes que pongan más el acento en el desarrollo y la cohesión territorial que en el crecimiento, que antepongan la cultura, la historia y criterios sostenibles a cualquier otra opción o práctica que persiga la rentabilidad electoral a corto plazo o el beneficio inmediato. Discursos positivos, propositivos y participados por una ciudadanía que ha de estar implicada y comprender que cuando un territorio o un paisaje irrepetible se pierde, desaparece una parte de su historia y de su cultura. $\mathrm{Ha}$ de conseguirse que esta forma de pensar ocupe el centro del imaginario colectivo. Porque este es, sobre todo, un reto que afecta al conjunto de la sociedad, que desborda ampliamente expresiones políticas y límites administrativos. $Y$ es desde el trabajo que haga posible que los contextos sociales cambien desde donde será posible conseguir cambiar la percepción social mayoritaria en relación con la utilización de sus recursos o de su paisaje como cultura, bien público y legado. Es en esos casos cuando las políticas, más coordinadas, con mayor voluntad de cooperación y más claras, ganan en eficacia.

Los pueblos más cultos de Europa han sido capaces de alcanzar un respetuoso equilibrio entre cultura, historia, territorio, identidad, modernidad y competitividad. Siempre de acuerdo con una secuencia muy parecida a la que antes se ha hecho referencia: en primer lugar, la comunidad científica alerta sobre prácticas y situaciones indeseables o insostenibles, después los medios de comunicación se hacen eco, posteriormente amplios sectores de la ciudadanía lo incorporan como problema o como reto colectivo y finalmente esta percepción mayoritaria acaba por impregnar las políticas públicas. Nosotros estamos ahora al inicio del proceso. Muchos paisajes culturales ya serán irrecuperables, pero otros muchos se podrán mantener intactos. $\mathrm{Y}$ las malas prácticas dejarán de ser aplaudidas (y apoyadas en elecciones) para ser sancionadas por la mayoría de la población.

Muchos ciudadanos europeos participamos de la idea de que el futuro del territorio y del paisaje depende en gran parte de la existencia de una vigorosa sociedad civil que sea capaz de mirar con respeto, con sensibilidad y con cultura, con civilidad en definitiva, hacia atrás y hacia delante. Sabiendo que el territorio y el paisaje no son patrimonio exclusivo de nadie, que no somos los únicos, tampoco los primeros ni los últimos. Que no somos el centro de la Naturaleza. Ya disponemos de buenas prácticas en las que sus impulsores han sido capaces de conservar sus paisajes porque son parte de esa historia colectiva. Han preferido conservarlos y mantenerlos vivos antes que abandonarlos. Nosotros debemos ser capaces de hacer lo propio. Sabiendo que las funciones de muchos de esos territorios ya no será la de producir alimentos y dedicarlo a pastos, pero sí pueden realizar otras funciones ecológicas, culturales y reparadoras de gran utilidad para la colectividad.

En la Unión Europea diversos Estados y muchas regiones con poder legislativo hace tiempo que han apostado por una nueva concepción estratégica basada en una nueva cultura del territorio y del paisaje. Han apostado decididamente por el impulso de estrategias compartidas y enfoques integrados en detrimento de los sectoriales; desarrollan marcos de actuación supramunicipales y regionales, superadores del excesivo minifundismo municipal; impregnan las políticas públicas de elementos clave, como cooperación institucional (formal e informal), desarrollo y cohesión territorial; parten de la aplicación del principio de equidad entre personas, entre territorios y entre generaciones... Es decir, están empeñados en sentar marcos claros y sostenibles de buen gobierno y 
de gobernanza democrática territorial. En este "giro territorial" de las políticas públicas, Europa puede contribuir de forma apreciable a asentar nuevas formas de buen gobierno del territorio. Pero la responsabilidad fundamental corresponde básicamente a la ciudadanía y a los poderes públicos españoles. El futuro del territorio y del paisaje en España depende en gran medida de la existencia de una vigorosa sociedad civil.

Nuestra mayor debilidad reside en la incapacidad para identificar, consensuar e impulsar de forma coordinada una agenda real para desarrollar un conjunto de políticas públicas a favor de una mayor cohesión y coherencia territorial. Nuestro mayor problema ya no es de información. Sobran diagnósticos elaborados a escala local, regional, estatal y europea. Sobran planes y proyectos. Sobra retórica. Falta voluntad política, más democracia y una sociedad civil más organizada y comprometida para adentrarnos en el camino de la buena gobernanza democrática y del buen gobierno del territorio. En este trabajo de largo recorrido la comunidad académica y profesional tiene ante sí una responsabilidad ineludible.

\section{Referencias}

ALFAMA, Eva; CASADEMUNT, Álex; COLLPLANAS, Gerard; CRUZ, Helena; MARTÍ, Marc. Per una nova cultura del territori? Mobilitzacions i conflictes territorials. Barcelona: Icaria, 2007.

BERGER, John. Puerca tierra. Madrid: Alfaguara, 2006.

CAMPAIGN TO PROTECT RURAL ENGLAND. CPRE's guide to Quiet Lanes, septiembre de 2006.

CAMPAIGN TO PROTECT RURAL ENGLAND. Campaigning for the beauty, tranquility and diversity of the countryside. Octubre, 2006.

CERRILLO, Agustí (Coord.). La gobernanza hoy: 10 textos de referencia. Madrid: INAP.

COLEGIO DE GEÓGRAFOS DE ESPAÑA Y COLEGIO DE ARQUITECTOS (2006): Manifiesto por una nueva cultura del territorio. 2006. <http//www.geografos.org>. (Consultado el 2 de abril de 2011).

CRUZ I GALLACH, Helena. La veu de la ciutadania en el planejament urbanístic. Una reflexió sobre la conflictivitat territorial a Catalunya. Tesis doctoral inédita, Universitat Autònoma de Barcelona, 2010.

DAVOUDI, Simin. Cohesión territorial: relaciones con la planificación territorial y la política regional. In FARINÓS, J.; ROMERO, J. (Eds.). Territorialidad y buen gobierno para el desarrollo sostenible. Nuevos principios y nuevas políticas en el espacio europeo. Valencia: Publicaciones de la Universitat de València, 2007, p. 67-76.

ESPON. Governance of territorial and urban policies from the EU to the local level. Final Report 2.3.2. 2006.

ESPON. New Evidence on Smart, Sustainable and Inclusive Territoires. First ESPON 2013 Syntesis Report, Luxembourg. 2010.

FISCALÍA GENERAL DEL ESTADO. Memoria al Gobierno de S.M. presentada al inicio del año judicial por el Fiscal General del Estado, Fiscalía Coordinadora de Medio Ambiente y Urbanismo. Madrid: Ministerio de Justicia, Secretaría General Técnica, 2 vols, 2007.

HENDERSON, Ailsa. Why Regions Matter: Substate Polities in Comparative Perspective. Regional and Federal Studies, 2010, vol. 20, n 45, p. 439-445.

MACKAY, Charles. Memoirs of Extraordinary Popular Delusions and the Madness of Crowds. Londres, segunda edición, 1852. Disponible on line

en: <http://www.econlib.org/Library/Mackay/macExc over.html>. (Consultado el 12 de abril de 2011), MARTÍNEZ DE PISÓN, Eduardo. Miradas sobre el paisaje. Madrid: Biblioteca Nueva, Colección Paisaje y Teoría, 2009.

MATSUDA, Yasuhiko (Coord.). Gobernabilidad 
democrática en México: más allá de la Captura del Estado y la Polarización Social. Washington: Banco Internacional de Reconstrucción y Fomento/ Banco Mundial, 2007.

MATA, Rafael y TARROJA, Álex (Coord.). El paisaje y la gestión del territorio. Criterios paisajísticos en la ordenación del territorio y el urbanismo. Barcelona: Diputació de Barcelona, serie Territorio y Gobierno: Visiones, n 5, 2006.

MATEU, Joan y NIETO, Manuel (Eds.). Retorno al paisaje. El saber filosófico, cultural y científico del paisaje en España. Valencia, EVREN, 2008.

NAREDO, José Manuel y MONTIEL, Antonio. El modelo inmobiliario español y su culminación en el caso valenciano. Barcelona: Icaria, 2011.

NOGUÉ, Joan (Ed.). La construcción social del paisaje. Madrid: Biblioteca Nueva, 2007.

NOGUÉ, Joan (Ed.). Paisatge i salut. Barcelona: Observatori del Paisatge de Catalunya, Sèrie Reflexions, 2008.

NOGUÉ, Joan. Entre paisajes. Barcelona: Àmbit, 2008.

NOGUÉ, Joan et al. (Eds.). Indicadors de paisatge. Reptes i perspectives. Barcelona: Observatori del Paisatge de Catalunya y Obra Social La Caixa, 2009.

PASCUAL, Josep María ; GODÀS, Xavier (Coord.). El buen gobierno 2.0: la gobernanza democrática territorial. Valencia: Tirant Lo Blanch, 2010.

PÉREZ, Francisco. La crisis en España: la herencia de un crecimiento desequilibrado. In MARTÍN ACEÑA, P. (Ed.). Pasado y presente: de la Gran Depresión del siglo XX a la Gran Recesión del siglo XXI. Madrid: Fundación BBVA, 2011, p. 252-282.

PIKE, Andy; RODRÍGUEZ-POSE, Andrés; TOMANEY, John. Desarrollo local y regional. Valencia: Publicaciones de la Universidad de Valencia, Colección Desarrollo Territorial, $\mathrm{n}^{\circ} 8$, 2011.

PRATS, Joan. Modos de gobernación de las so- ciedades globales. In CERRILLO, A. (Coord.). La gobernanza hoy: 10 textos de referencia. Madrid: INAP, 2005, p. 145-172.

ROMERO, Joan. España inacabada. Valencia: Publicaciones de la Universitat de València, 2006.

ROMERO, Joan. Geopolítica y gobierno del territorio en España. Valencia: Tirant Lo Blanch, 2009.

ROMERO, Joan. Construcción residencial y gobierno del territorio en España. De la burbuja especulativa a la recesión. Causas y consecuencias. Cuadernos Geográficos de la Universidad de Granada, nº 47 (2010-2), p. 17-46.

ROMERO, Joan; FARINÓS, Joaquín. Redescubriendo la gobernanza más allá del buen gobierno. Democracia como base, desarrollo territorial como resultado. Boletín de la Asociación de Geógrafos Españoles, nº 56 (2011), p. 295319.

SMITH, Graham. Democratic innovations. Designing Institutions for Citizen Participation, London: Cambridge, 2009.

SOJA, Edward W. La perspectiva postmoderna de un geógrafo radical. Edición crítica a cargo de Núria Benach y Abel Albet. Barcelona: Icaria, 2010.

SUBRA, Philippe. Géopolitique de l'aménagement du territoire. Paris: Armand Colin, 2007.

\section{Cita del artículo}

ROMERO, J. ¿Territorios inteligentes, sostenibles e inclusivos? Enseñanzas de la experiencia española. Hábitat y Sociedad, 2011, n² 2, p. 13-32. $<\underline{w w w . h a b i t a t y s o c i e d a d . u s . e s>}$. http://dx.doi.org/10.12795/HabitatySociedad.2011.i2.02 